\title{
CLIENTS' PERCEPTIONS ON SULFADOXINE-PYRIMETHAMINE (SP) USE AS A FIRST LINE ANTI-MALARIAL DRUG IN BAGAMOYO DISTRICT, TANZANIA SEPTEMBER 2005
}

\author{
By Rweyemamu, Irene (MD 4 - 2005/2006)
}

\begin{abstract}
Objectives: To assess clients' perceptions on Sulfadoxine- Pyrimethamine (SP) use as a first line anti-malarial drug in Bagamoyo district, Tanzania and put forward intervention strategies based on the obtained findings.
\end{abstract}

Design: Community based Cross-sectional descriptive study.

Settings: Bagamoyo district in the Coastal region, Tanzania.

Subjects: All individuals aged 15-49 who were present in the sampled households during the time of study.

Results: More than half of the study population (52.1\%) perceived SP as a bad drug, $44.5 \%$ of them thought that the drug was unsafe for use and $49.9 \%$ of them were not ready to use it for malaria treatment in future. However most of them had no knowledge on the drug itself, its course of action and the expected outcomes after using it.

Recommendation: There is a great need for mass education regarding the drug, its actions, possible side effects and how to overcome these side effects if possible when introducing drugs that are recommended by the national guidelines and especially those that are widely used by the community like SP.

\section{Correspondence to:}

Irene Rweyemamu, +255-741-143-542.

\section{INTRODUCTION}

Over the globe malaria was and still is a threat to the well being of individuals, families, societies and nations at large. There are approximately 300 million acute cases of malaria annually resulting in more than a million deaths. About $90 \%$ of these deaths occur in Africa south of the Sahara.

Pregnant women and children under five years of age are particularly vulnerable to malaria ${ }^{1}$. In
Tanzania malaria remains endemic over the majority of the country and it is the leading cause of morbidity and mortality ${ }^{2}$.

Throughout years, a number of anti-malarials have been produced and adopted by the world market to cut down the malaria associated morbidity and mortality rates. However malaria parasites have been and are still developing unacceptable levels of resistance to one drug after another thus most of these drugs are no longer useful.

Tanzania faced an average of $42 \%$ of chloroquine failure rates in 1999 thus the change of its malaria treatment policy was inevitable ${ }^{3}$. chloroquine was officially banned in August 2001 and SP was then adopted as the first line drug.

SP has few untoward effects if used carefully in therapeutic doses. Nausea, vomiting, generalized body weakness; diarrhea, skin rashes and hematological reactions are some of the associated side effects. The drug can cause severe skin reactions such as Steven Johnson's syndrome. This is quite rare but can be fatal particularly in patients who are immune compromised ${ }^{4}$.

Despite these known facts, the community shows reluctance in using the drug because it is perceived to be too strong. Most people are not ready to use the drug because of the fear of associated side effects.

Experience from the introduction of SP as a first line treatment in neighboring countries of Kenya and Malawi shows that, people continue to use chloroquine after the introduction of the new drug due to the fear that a potent drug could be dangerous ${ }^{3}$.

In Tanzania most parents and some providers expressed fear of adverse reactions following SP use and had negative perceptions towards SP. A study done in Kibaha district in 2000 showed that SP was perceived to be too strong for children ${ }^{5}$.

Another study done in Muheza district in 2002 states that majority of people were unwilling to use SP based on severe adverse reactions particularly skin lesion known as Steven Johnson's syndrome 
[kubabuka] and inducing general body weakness [kuvunjavunja mwili $]^{6}$.

The study further reports that in children below five years of age and pregnant mothers SP was reported by the majority to be unsafe because it increases body temperature and there is fear of inducing spontaneous abortion among pregnant women.

Specific counseling to parents on what they should expect regarding the course of the disease after SP administration was suggested ${ }^{7}$. Results obtained by Dr E.N. Nsimba supported the need for these both in relation to SP's effects on fever and the perceived high risk of side effects. Communities need to have better knowledge, understanding and perceptions of the drugs positive and negative effects ${ }^{7}$.

About four years have elapsed since the drug was officially introduced. The community is thus expected to have better knowledge on the side effects of the drug which would in turn contribute to their positive perception towards it. This study thus aimed at assessing the present situation with regard to civilians' perceptions towards SP and at the end come up with recommendations basing on the obtained findings.

\section{METHODOLOGY}

Community based Cross sectional descriptive study. A two staged stratified sampling procedure was employed. Two wards of Dunda and Majani Mapana were selected randomly by tossing a coin. Out of the wards several households were randomly chosen. Samples included all individuals aged 15-49 in the selected households.

Data was collected using a structured Swahili questionnaire. Questions were posed to the samples and they responded to them.

Permission to conduct the study was sought from the MUCHS research committee, then the district officer of Bagamoyo and ward officers of Dunda and Majani Mapana. Informed consent was obtained from the study participants before administering the questionnaire.

\section{RESULTS}

The study involved a total of 384 subjects out of which $217(56.5 \%)$ were females and $167(43.5 \%)$ males. Majority of the subjects $(28.9 \%)$ were aged 20 to 24 years.

\section{TABLE 1: RESPONSE TO SAFETY OF SP IN MALARIA TREATMENT AMONG THE STUDY POPULATION BY SEX}

\begin{tabular}{|c|c|c|c|c|c|c|c|c|}
\hline & \multicolumn{8}{|c|}{ SP SAFE } \\
\hline \multirow{2}{*}{$\begin{array}{l}\text { SEX } \\
\text { FEMALE }\end{array}$} & \multicolumn{2}{|c|}{ YES } & \multicolumn{2}{|c|}{ NO } & \multicolumn{2}{|c|}{ I DON'T KNOW } & \multicolumn{2}{|c|}{ TOTAL } \\
\hline & & $(35.0 \%)$ & 92 & $(42.4 \%)$ & & $(22.6 \%)$ & 217 & $(100.0 \%)$ \\
\hline MALE & & $(25.7 \%)$ & 79 & $(47.3 \%)$ & & $(26.9 \%)$ & 167 & $(100.0 \%)$ \\
\hline TOTAL & 119 & $0 \%)$ & 171 & $(44.5 \%)$ & 94 & $(24.5 \%)$ & 384 & $(100.0 \%)$ \\
\hline
\end{tabular}

About 5 out of 10 interviewees (44.5\%) perceived SP to be an unsafe drug while $31.0 \%$ found it to be safe.

TABLE 2: KNOWLEDGE ON THE ACTION OF SP ON FEVER BY SEX

\begin{tabular}{|l|l|l|l|l|}
\hline & \multicolumn{5}{|c|}{ SP DROPS FEVER } \\
\hline SEX & YES & NO & I DON'T KNOW & TOTAL \\
\hline FEMALE & $88(40.9 \%)$ & $67(30.7 \%)$ & $62(28.4 \%)$ & $217(100.0 \%)$ \\
\hline MALE & $67(40.4 \%)$ & $46(27.3 \%)$ & $54(32.3 \%)$ & $167(100.0 \%)$ \\
\hline TOTAL & $155(40.7 \%)$ & $113(29.3 \%)$ & $116(30.1 \%)$ & $384(100.0 \%)$ \\
\hline
\end{tabular}

Most people (40.7\%) thought that SP can drop fever with the proportion more or less similar between the two sexes and $29.3 \%$ knew that SP cannot drop fever. 
TABLE 3: KNOWLEDGE ON THE RISK FACTORS FOR STEVEN JOHNSON'S SYNDROME (SJS) FOLLOWING SP USE AMONG THE STUDY POPULATION BY SEX

\begin{tabular}{|c|c|c|c|c|c|c|}
\hline & \multicolumn{6}{|c|}{ KNOWLEDGE ON THE RISK FACTORS } \\
\hline SEX & & & & & & AL \\
\hline FEMALE & 42 & $(19.4 \%)$ & 175 & $(80.6 \%)$ & 217 & $(100.0 \%)$ \\
\hline MALE & 30 & $(18.0 \%)$ & 137 & $(82.0 \%)$ & 167 & $(100.0 \%)$ \\
\hline TOTAL & & $(18.8 \%)$ & 312 & $(81.2 \%)$ & 384 & $(100.0 \%)$ \\
\hline
\end{tabular}

Most of the interviewees (81.2\%) did not know the risk factors for developing SJS following SP use, this proportion was more or less similar in both sexes.

\section{GRAPH 1: PERCEPTIONS ON SP AS THE FIRST LINE DRUG IN MALARIA TREATMENT}

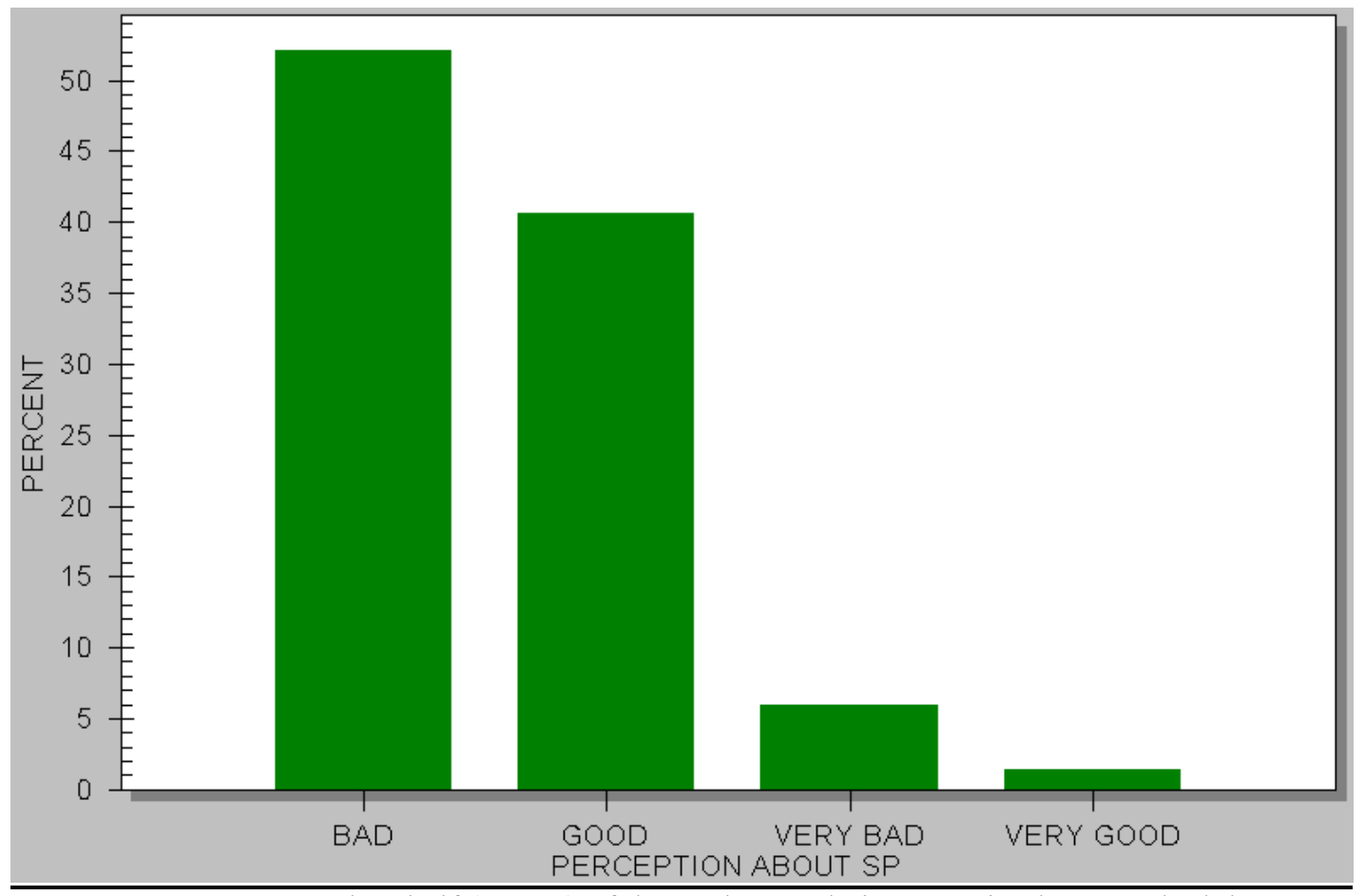

More than half (52.1\%) of the study population perceived SP as a bad drug

\section{DISCUSSION}

More than half of the study population (52.1\%) perceived SP as a bad drug, $44.5 \%$ of them thought that the drug was unsafe for use and $49.9 \%$ of them were not ready to use it for malaria treatment in future. This compares well with a study done in Kibaha district Tanzania by Tarimo, D.S., Minjas J.M., Bygbjerg I.C. in 2002 were most people had negative attitudes towards the drug.

$76.0 \%$ of the population reported to have used SP in the past. $27.0 \%$ of those who had used SP before reported to have developed side effects, the commonest reported side effects being body malaise and fever. From this population only 3.2\% reported to have developed Steven Johnson's Syndrome (SJS) following SP use. This concurs with the known facts that most side effects due to SP are minor and the severe side effects like the SJS are very rare ${ }^{4}$.

$59.4 \%$ of the population thought that SP use can lead to side effects, most of them (41.2\%) reporting that SP use can result into Steven Johnson's Syndrome (SJS). This is similar to the results obtained in Muheza district in 2002 where most people were unwilling to use SP due to the severe skin reactions associated with it. 
$30.1 \%$ of the population knew that SP does not drop fever as compared to $40.7 \%$ who thought that the drug drops fever. This depicts a discrepancy that exists in this community with regards to the correct knowledge on the actions of SP specifically its non-antipyretic action. This is probably why fever was reported by $19.0 \%$ of SP users to be one of the SP side effects.

Even those who knew that SP does not drop fever, only 5 out of $10(53.6 \%)$ people knew that paracetamol $\left(\right.$ Panadol $\left.^{\circledR}\right)$ or aspirin i.e. an antipyretic was supposed to be used with SP to drop the fever. This further signifies that a big number of people are not aware of the course of action and the expected outcomes after SP use a recommendation that was made from a study done in Muheza district Tanzania in 2002.

Majority of people $(61.5 \%)$ did not know that the common side effects due to SP e.g. nausea and body malaise could be reduced as compared to $28.2 \%$ who knew. $61.7 \%$ of those who knew were able to mention drinking a lot of water and taking sugary foods as options to the reduction of these side effects.

Only 3 out of $100(3.2 \%)$ of the SP users had developed the SJS. $18.8 \%$ of the population reported to know the risk factors for developing the syndrome, out of which only $3.2 \%$ reported sulfur as the factor behind the syndrome. The other reported risk factors were immunodeficiency, blood type, age, low body weight and usage of body creams.

$81.2 \%$ of the population did not know the risk factors for developing the SJS and thought that every SP user is at risk of developing the syndrome. This is probably why most people (44.5\%) regarded the drug as being unsafe.

\section{CONCLUSION}

Majority of people had negative attitudes towards $\mathrm{SP}$ as the first line anti-malarial drug in malaria treatment. However, most of them had no knowledge on the drug itself, its course of action and the expected outcomes after using it.

A few of them had developed the minor side effects due to SP use and very few had developed severe side effects but still most of them perceived the drug negatively. Most of these people had no knowledge on the risk factors for developing such side effects so their perceptions were mainly psychological.

\section{RECOMMENDATIONS}

There is a great need for mass education when introducing drugs that are recommended by the national guidelines and especially those that are widely used by the community like SP

Health practitioners should do their best to enforce the education at individual level when prescribing drugs.

Women in reproductive age who keep on using SP for Intermittent Presumptive treatment (IPT) should be educated on the drug and especially its side effects to ensure good compliance.

Studies should be carried out to target communities on the actions and acceptability of the drug before embarking on adopting it as the first line drug.

\section{REFERENCES}

1. www.who.int $/ \mathrm{malaria} / \mathrm{rbm}$

2. WHO; World Report; May 2004

3. Bloland P.B. and Bttling M. (1999); Making malaria treatment policy in the face of drug resistance, Annals of Tropical Medicine and Parasitology, 93:5-22

4. Rang H.P. et al (2003) Antimalarial drugs; In Pharmacology; Bath Press, U.K; chp n pgs

5. Tarimo, D.S. Minjas J.M., Bygbjerg I.C. (2001b) Perception of Chloroquine efficacy and alternative treatments for uncomplicated malaria in children in holoendemic area of Tanzania; implication for the change of treatment policy Tropical Medicine International Health 6:992 - 997.

6. Massaga J.J et al. (2003) 'Knowledge, Attitudes and Practices towards the national malaria treatment policy change in Tanzania'; NIMR Annual Report; Dar-es salaam, Tanzania; 26-27

7. Nsimba E.D, (2002) Exploring malaria case management of under five children in households and public primary health care facilities in Kibaha District Tanzania; PhD Thesis, Karolinska Institute, Stockholm Sweden. 